\title{
Determinants of Participation Decision and Levels of Participation in Small Ruminants Market
}

\author{
Yonas Kassahun $^{1,2}$, Mengistu Ketema ${ }^{2} \&$ Zekarias Shumeta $^{3}$ \\ ${ }^{1}$ College of Agriculture and Natural Resource Sciences, Debre Birhan University, Ethiopia \\ ${ }^{2}$ School of Agricultural Economics \& Agribusiness, Haramaya University, Ethiopia \\ ${ }^{3}$ Ethiopian Agricultural Research Council Secretariat, Ethiopia \\ Correspondence: Yonas Kassahun, College of Agriculture and Natural Resource Sciences, Debre Birhan \\ University, Ethiopia. E-mail: yonasfantaye4@gmail.com
}

Received: October 19, 2019

Accepted: December 4, 2019 Online Published: January 2, 2020

doi:10.5539/sar.v9n1p56

URL: https://doi.org/10.5539/sar.v9n1p56

\begin{abstract}
Small ruminants are mainly kept for immediate cash sources and they are also sources of foreign currency. Nonetheless, there is a lack of well-functioning marketing systems. In addition, the different live animals supplied to the market by pastoralists and farmers do not meet the quality attributes required by diverse markets. Randomly 1120 farmers were selected and using double hurdle model, the article identified determinants of participation decision and level of participation in small ruminants market in 7 districts of five regional states of Ethiopia. Out of the total interviewed households, $77.3 \%$ and $22.7 \%$ were participated and not-participated to the small ruminants market, respectively. The first-hurdle model estimation results for participation decision indicate that Region, access to credit, distance to the market, distance to veterinary service, extension contact and access to market information were found that significantly influenced small ruminants' market participation The results also show that most of the factors determining decision of participation also determined the level of small ruminants market participation. Therefore, government or any other bodies who are concerned on small ruminants product should help producers on Improving the accessibility of market places; need to facilitate a long term relationship with different actors in order to get reasonable price for the producers.
\end{abstract}

Keywords: determinants, participation decision, small ruminants farmers, Ethiopia

\section{Introduction}

Livestock sectors play vital roles in generating income to farmers, creating job opportunities, ensuring food security, providing different services, contributing to asset, social, cultural, and environmental values, and sustaining livelihood strategies of peoples (Mohammed, 2019). Small ruminants are integral part of livestock keeping in Sub-Saharan Africa that are mainly kept for immediate cash sources, milk, meat, wool, manure, and saving or risk distribution (Matawork, 2016 and Dessalegn, 2018). They are also sources of foreign currency (Shewangzaw, Aschalew, Addis, Malede \& Assemu, 2018). They are one of the major sources of revenue in Ethiopia comprising about 30.70 million heads of sheep and 30.20 million heads of goat in the nation. Most of these sheep and goats are distributed across various agro-ecological zones of the nation (Central Statistical Agency [CSA], 2017).

Nonetheless, there are a lot of factors that hinders sheep and goats production yet they can be overcome on account of the uncountable opportunities which they possess (Chiemela, Seung-Hwan, Egbu, Prabuddha \&Jun Heon, 2018). Sheep and goat in Ethiopia and most developing regions are kept under traditional extensive systems (Shewangzaw et al., 2018). It is also suggested that the small-ruminant subsector generally had low levels of technical productivity (i.e. animal health and fodder quality) and decisions to sell stock were usually motivated by immediate cash needs, rather than by the goal of maximizing profits or generating a steady income (Mueller, Acero \& Estruch, 2017). Due to the low productivity of the animals and the absence of market-oriented production systems, the volume of marketed surplus is very low. In addition, the different live animals supplied to the market by pastoralists and farmers do not meet the quality attributes required by diverse markets. This is because of poor link of producers and other actors in the chain to the critical support services (Eyob and Zewudu, 2016). 
The performance of the existing sheep and goat marketing system also influenced by several factors. First, there is a lack of well-functioning marketing systems that effectively link many smallholder producers and their cooperatives with domestic and international markets. The available marketing system has so far not encouraged sheep producers to coordinate and collaborate into producing market oriented products. Unless producers are organized and jointly act in various activities including procurement of medicines, supplementary feeds and marketing, the transaction costs of marketing for individual sheep producers will remain high (Daniel, Solomon \& Getachew, 2013 and Duguma et al., 2013).

In spite of the market importance, a farmer's ability to take advantage of the existing market opportunities is highly dependent on personal and institutional factors. Namazzi, Ekere, Kyazze \& Bareeba, (2015) further explain that literacy level of a farmer has a positive effect on the level of participation in the market as it determines how the farmer makes marketing decisions and interprets market signals.

In order to shift small ruminants' production from subsistence to a more commercial outlook, it is important to understand aspects of goat and sheep market and marketing (Hosri, Tabet \& Nehme. 2016).Therefore, the objective of this paper is to determine the key factors that affect smallholder farmers' decisions to market as well as those that affect quantities sold when they participate in the market. The study takes the case of the small ruminants sector in Ethiopia where there has been much emphasis on production but where pertinent marketing information is lacking.

\section{Data and Methodology}

This study was conducted in 7 locations (districts) of five regional states of Ethiopia (i.e., Amhara, SNNP, Oromia, Somalia and Tigray regions). These research sites are already selected with the purpose of developing benchmarks for the interventions that are to be identified and implemented by ICARDA and its local partners along the small ruminant value chains.

Multistage sampling technique was used to select districts and kebeles based on small ruminants' production potential. Then, in order to use similar approaches in all the districts, a sample size of 160 producers were selected randomly in each district (i.e., Menz and Abergelea districts from Amhara region, Horro and Yabelo districts from Oromia, Doyogena from SNNP, Atsbi from Tigray and Shinille from Somalia) constituting a total of 1120 households (160 from each district).

The descriptive statistics analysis using t-test and chi-square test statistics were employed to compare groups based on market participation status (non- participant and participant farmers). To analyze determinants of market participation decision and level of participation in the small ruminants' market, double hurdle model was used. The specifications of the empirical models used to identify these determinants follow the models widely discussed in the participation literature (Esther and Gaudiose, 2016; Ali, 2017; Ayantu, 2018; Nugusa, 2018). In the model, the decision to participate can be seen as a sequential two-stage decision making process. In the first-stage, farmers make a discrete decision whether or not to participate in market activity of small ruminants. In the second-stage, conditional on their decision, farmers make continuous decision on the level of participation in the market.

The double-hurdle model is an extension of the Tobit model in which the requirement for simultaneous selection and quantity decisions are relaxed and it also allows for censoring at both decision stages. Hurdle models concern bounded outcomes. In this sense, hurdle models are much like tobit models. They differ in that hurdle models provide separate equations for the bounded and the unbounded outcomes, whereas tobit models use the same equation for both.

The Tobit model is an econometric model which was used in different studies to analyze determinants of probability of participation and level of participation of smallholder producers in market supply. In this model, the participation decision and level of participation of producers in market supply can be determined concurrently by the same variables as the variable which affect the probability of participation also affect the intensity of participation or total marketed volume (Ali, 2017).

Again, Heckman selection model was tested for the analysis of the data. However, the inverse mill's ratio was insignificant indicating that there was no difference between participants and non-participants in terms of market supply. As a result, double hurdle model is considered since the two decisions are independent and it assumes no correlation between the errors of the first and second equation, conditional on a properly specified model (Wooldridge, 2006).

Cragg's Double hurdle model (Cragg, 1971) involves two-step estimation procedures. The models use the Probit model in the first step to determine the probability of participating in the market and the second stage uses a 
truncated model to evaluate factors influencing the quantity of produce sold in the market. The two decisions are, therefore, whether to participate in the market and level of participation. This implies that households must cross two hurdles in order to sale the product.

We used the probit model followed by the truncated regression model was used to analyze factors determining the quantity of small ruminants in TLU marketed as specified by Wooldridge (2002):

$$
\begin{gathered}
Y_{i}^{*}=\mathrm{X} \beta+\mathrm{e}_{\mathrm{i}} \\
Y_{i}=\left\{\begin{array}{r}
1 \text { if } Y_{i} *>0 \\
0 \text { if } Y_{i} * \leq 0
\end{array}\right\}
\end{gathered}
$$

Where,

$\mathrm{Y}^{*}=$ is a latent variable representing producers' discrete decision whether to participate in the market or not

$\mathrm{X}=$ is a vector of independent variables hypothesized to affect producer's decision to participate in the market

$\beta=$ is a vector of parameters to be estimated which measures the effects of explanatory variables on the producer's decision

$\mathrm{e}_{\mathrm{i}}=$ is normally distributed disturbance term with mean (0) and standard deviation of (1), and captures all unmeasured variables

$Y_{i}=$ is a dependent variable which takes on the value of 1 if the producers participate in the market and 0 otherwise.

Then, the truncated regression uses observations only from producers whose values of small ruminants is positive or greater than zero. The intensity of supply of small ruminants is modeled as a regression truncated at zero:

$$
\begin{gathered}
Z_{i}^{*}=\mathrm{X} \beta+\mu_{i o}, \mu_{i o} \sim \mathrm{N}\left(0, \delta^{2}\right) \\
Z_{i}=\left\{\begin{array}{c}
Z_{i} * \text { if } Z_{i} *>0 \text { and } Y_{i}=1 \\
0 \text { otherwise }
\end{array}\right\}
\end{gathered}
$$

Where $\mathrm{Zi}$ is the intensity level of value which depends on latent variable $\mathrm{Z}_{\mathrm{i}}^{*}$ being greater than zero and conditional to the decision to value Yi.

If both decisions are made by the individual farmer independently, the error terms are assumed to be independently and normally distributed as: $\mu_{i} \sim N\left(0, \sigma^{2}\right)$.

According to Cragg (1971), log likelihood function for the double hurdle model that nests a univariate probit model and a truncated regression model is specified as follows.

Where,

$$
\log L=\sum \ln \left[1-\boldsymbol{\Phi}\left(Z_{i}{ }^{\prime} \alpha\right)\left[\frac{X_{i}^{\prime} \beta}{\alpha}\right]\right]+\sum_{+} \ln \left[\boldsymbol{\Phi}\left(Z_{i}^{\prime} \alpha\right) \frac{1}{\sigma} \phi\left[\frac{y_{i-x_{i}{ }^{\prime} \beta}}{\sigma}\right]\right]
$$

$\boldsymbol{\Phi}=$ represent standard normal probability

$\phi=$ density functions

$Z_{i}{ }^{\prime}=$ independent variables for the probit model

$X_{i}{ }^{\prime}=$ truncated regression model

$\alpha, \sigma$ and $\beta$ are parameters estimated from each model.

Recent empirical studies have shown the inadequacy of the Tobit model in cross-sectional analysis as it is statistically restrictive because it assumes that the same set of variables determine both the probability of non-zero participation and level of participation. In the other way, McDowell (2003) tested how to choose the best model between Tobit and Double-hurdle model. As such the double hurdle model likelihood function can always be maximized, without loss of information, by maximizing the two components separately.

Therefore, whether a Tobit or a double hurdle model is more appropriate can be determined by estimating the Tobit and the double hurdle models (the truncated regression model and the probit model) separately and then conducting a likelihood ratio test that compares the Tobit with the sum of the log likelihood functions of the probit and truncated regression models. The likelihood ratio test statistics can be computed (Greene, 2000) as follows: 
Where,

$$
\Gamma=-2\left[\ln L_{\text {Tobit }}-\left(\ln L_{\text {Probit }}+\ln L_{\text {Truncated }}\right)\right] \sim \chi_{k}^{2}
$$

$\Gamma=$ Likelihood ratio statistic

ln= natural logarithm

$L_{\text {Tobit }}, L_{\text {Probit }}$ and $L_{\text {Truncated }}$ are likelihood values for Tobit, Probit and Truncated models

$\chi^{2}=$ Chi-square statistic

$\mathrm{k}=$ number of explanatory variables in the equations

Thus, the decision rules to reject the null hypothesis (i.e., both the participation and level of participation to the market are affected by the same set of factors) if the likelihood ratio $(\Gamma)$ exceeds the value of the chi-square test $\left(\chi_{k}{ }^{2}\right)$ from the table at the certain degree of freedom by a given significance level.

\section{Definition of Variables and Working Hypotheses}

\section{Dependent variable}

Small ruminants' market participation decision: It is a dummy dependent variable that represents the probability of market participation of the producers in the market that is regressed in the first stage of the double hurdle estimation procedures. For the household who participate in the market, the variable takes the value of 1 where as it takes the value of 0 for the household who does not participate in the small ruminants market within a year.

Quantity of small ruminants in TLU: It is a continuous dependent variable in the second step of the double hurdle model. It was measured in number of Tropical Livestock Units (TLU) and represents the actual supply by small ruminants producing households to the market in the survey year.

\section{Explanatory variables}

The hypothesized explanatory variables listed below are selected based on economic theory and previous studies on nature of the study and the summary of variables description and hypothesis is also depicted in the following table:

Table 1. Summary of variables description and hypothesis

\begin{tabular}{|c|c|c|c|}
\hline Variables & Type & Value & Expected sign \\
\hline Region & Categorical & $\begin{array}{l}\text { 1-Amhara, 2-Oromia 3-SNNP } \\
\text { 4-Somalia and 5-Tigray }\end{array}$ & $(+/-)$ \\
\hline Sex of the household head & Dummy & $\begin{array}{l}\text { 1-Male and } \\
0 \text {-Female }\end{array}$ & $(+)$ \\
\hline Age of the household head & Continuous & $\begin{array}{l}\text { Number } \\
\text { of years }\end{array}$ & $(-)$ \\
\hline $\begin{array}{l}\text { Educational status of the } \\
\text { household head }\end{array}$ & Dummy & $\begin{array}{ll}1- & \text { literate and } \\
0- & \text { illiterate }\end{array}$ & \\
\hline Family size & Discrete & Number of family members & $(-)$ \\
\hline Total hectare own & Continuous & Size of land & $(+)$ \\
\hline Distance to market place & Continuous & Distance in kilometer & $(-/+)$ \\
\hline Access to market information & Dummy & 1 -yes and 0 - no & $(+)$ \\
\hline Access to credit use & Dummy & 1 -yes and 0 - no & $(+)$ \\
\hline Distance to veterinary service & Continuous & Distance in kilometer & $(-/+)$ \\
\hline Extension contact & Discrete & In number of days & $(+)$ \\
\hline Other animals sale & Continuous & In TLU & $(-)$ \\
\hline Small ruminants slaughtered within a year & Continuous & In TLU & $(-)$ \\
\hline
\end{tabular}

\section{Result and Discussions}

In this section, the first section presents the descriptive statistics results of the study and this is followed by the discussion of econometric model results.

\subsection{Descriptive Analysis}

In order to understand and compare respondents' groups differences between non- participants and participants in small ruminants market, descriptive statistics such as mean, percentage, standard deviation, t-test and 
chi-square test were employed.

Out of the total 1108 interviewed households, $856(77.3 \%)$ were participated to the small ruminants market, and the remaining $252(22.7 \%)$ were non-participants to the market. The mean values of the continuous variables in both groups were compared using t-test. The test helps to check whether or not the mean values of a given continuous variable significantly differ between the two groups. Accordingly, the t-values of eight continuous variables were computed and out of these variables the two groups were found to differ significantly in two of them (Table 2).

There is non-significance mean difference in age, family size, distance to veterinary service, extension contact, TLU of other animal sale and TLU of slaughter small ruminants animals with in a year between market participant and non-participant farmers, which is evaluated using independent sample t-test at 5\% level of significance. Whereas, the computed t-test values indicate that the mean difference for two variables, namely land size and distance to the market were significant and indicated a negative relationship between participant and non-participant to the market is observed at $5 \%$ and $1 \%$ significance levels, respectively.

Land is the basic asset of farmers. The average size of land holding was about 0.98 hectare, the minimum and the maximum being 0.25 and 3 ha, respectively. Farmers participate to small ruminants market have on average larger area of land (1hactare) than farmers who do not participant to the market ( 0.92 hectare). The mean difference was significance at $5 \%$ level. This could also indicate, farmers with high land size may rather want to expand on crop sector or other activities than small ruminants sector as compared to those farmers who have small land size.

The average distance to market place in $\mathrm{km}$ is about $5.85 \mathrm{~km}$. On average, participant farmers traveled about $6.10 \mathrm{~km}$ while the non-participant households travelled $4.99 \mathrm{~km}$. The mean difference between the distance covered by participant and non-participant farmers to the market was statistically significant at $1 \%$ level of probability. This may probably indicate that, households who are closer to the market may have another alternative marketable product, a product which is better than small ruminants, encouraging them not to sell small ruminants.

Table 2. Characteristics of the sample households (Continuous)

\begin{tabular}{|c|c|c|c|c|c|c|c|}
\hline \multirow[t]{2}{*}{ Characteristics } & \multicolumn{2}{|c|}{$\begin{array}{l}\text { Non-participants } \\
\text { to market }(\mathrm{N}=252)\end{array}$} & \multicolumn{2}{|c|}{$\begin{array}{l}\text { Participant to } \\
\text { market }(\mathrm{N}=856)\end{array}$} & \multirow[t]{2}{*}{ T-value } & \multicolumn{2}{|c|}{ Total Sample } \\
\hline & Mean & $\begin{array}{l}\text { Standard } \\
\text { deviation }\end{array}$ & Mean & $\begin{array}{l}\text { Standard } \\
\text { deviation }\end{array}$ & & Mean & $\begin{array}{l}\text { Standard } \\
\text { deviation }\end{array}$ \\
\hline Age & 43.37 & 10.227 & 42.45 & 9.642 & 1.307 & 42.66 & 9.781 \\
\hline Family size & 6.09 & 2.362 & 6.25 & 2.232 & -.986 & 6.21 & 2.263 \\
\hline Land size $(\mathrm{Ha})$ & .92 & .410 & 1.00 & .401 & $-2.766 * *$ & .98 & .404 \\
\hline Distance from Mkt (km) & 4.99 & 2.350 & 6.10 & 3.277 & $-5.014 * * *$ & 5.85 & 3.124 \\
\hline Dist from vet. Services & 4.77 & 3.173 & 4.68 & 3.253 & .404 & 4.70 & 3.234 \\
\hline Extn Contact (No. of Days) & 14.57 & 12.782 & 14.72 & 13.486 & -.157 & 14.68 & 13.323 \\
\hline Other Animal sale (TLU) & .46 & .919 & .51 & .949 & -.789 & .50 & .942 \\
\hline Slaughtered Sheep Goat (TLU) & .04 & .087 & .05 & .090 & -.789 & .05 & .089 \\
\hline
\end{tabular}

Note: $* * *$ and $* *$ significance at $1 \%$ and $5 \%$

Source: Computed from the survey data

The chi-square test was also used to examine the existence of statistically significant difference between the groups. Accordingly, five variables were considered and the two groups were found to be different in terms of two of the five discrete variables (Table 3). Specifically, the chi-square test reveals that market information showed statically significant differences between the two groups at $5 \%$ probability level.

The result of the survey also indicates that on average $77.3 \%$ of the respondents in all these regions were participated to the small ruminants market, while $22.7 \%$ did not participate in the small ruminants market. $87 \%$ of Amahra region farmers assumed to have more impact on small ruminants market participation followed by Somali, Oromia, Tigray and SNNP region with a percentage of $82.1 \%, 78.2 \%, 71.6 \%$ and $55.9 \%$, respectively. The difference between these percentage figures was significant at $1 \%$ level. On the other hand, $44.1 \%, 28.4 \%$, $21.8 \%, 17.9 \%$, and $13 \%$ of farmers did not participate to small ruminants market in SNNP, Tigray, Oromia,Somalia and Amhara regions, respectively. 
It is widely accepted that substantial small ruminants' production increases could be achieved when farmers get appropriate market information. The survey result showed that about $77.3 \%$ of farmers got market information while only $22.7 \%$ of farmers did not have market information, with percentage difference significance at $5 \%$ level.

Table 3. Characteristics of the sample households (Discrete)

\begin{tabular}{|c|c|c|c|c|c|c|c|}
\hline \multirow[t]{2}{*}{ Characteristics } & \multicolumn{2}{|c|}{ Non-participants to market } & \multicolumn{2}{|c|}{ Participant to market } & \multirow[t]{2}{*}{ Chi-Square value } & \multirow[b]{2}{*}{ No. } & \multirow[b]{2}{*}{$(\%)$} \\
\hline & No. & $(\%)$ & No. & $(\%)$ & & & \\
\hline \multicolumn{8}{|l|}{ Region } \\
\hline $1=$ Amhara & 41 & 13 & 275 & 87 & & 316 & 28.5 \\
\hline $2=$ Oromia & 69 & 21.8 & 247 & 78.2 & $61.795^{* * *}$ & 316 & 28.5 \\
\hline $3=\mathrm{SNNP}$ & 67 & 44.1 & 85 & 55.9 & & 152 & 13.7 \\
\hline 4= Soamlia & 29 & 17.9 & 133 & 82.1 & & 162 & 14.6 \\
\hline 5= Tigray & 46 & 28.4 & 116 & 71.6 & & 162 & 14.6 \\
\hline \multicolumn{8}{|l|}{ Sex } \\
\hline $0=$ Female & 40 & 20.4 & 156 & 79.6 & .739 & 196 & 17.7 \\
\hline 1=Male & 212 & 23.2 & 700 & 76.8 & & 912 & 82.3 \\
\hline \multicolumn{8}{|l|}{ Education } \\
\hline $0=$ Illiterate & 149 & 21.7 & 103 & 24.5 & 1.220 & 252 & $22 . .7$ \\
\hline 1= Literate & 539 & 78.3 & 317 & 75.5 & & 856 & 77.3 \\
\hline \multicolumn{8}{|l|}{ MktInformation } \\
\hline $0=$ No Access & 122 & 26.2 & 344 & 73.8 & $5.406^{* *}$ & 466 & 42.1 \\
\hline 1=AccessMktInfo & 130 & 20.2 & 512 & 79.8 & & 642 & 57.9 \\
\hline \multicolumn{8}{|l|}{ CreditAcc Use } \\
\hline $0=$ NoCredAce & 194 & 23.6 & 627 & 76.4 & 1.416 & 821 & 74.1 \\
\hline $1=$ AcctoCred & 58 & 20.2 & 229 & 79.8 & & 287 & 25.9 \\
\hline
\end{tabular}

Note: $* * *$ and $* *$ significance at $1 \%$ and $5 \%$

Source: Computed from the survey data

\subsection{Results of Econometric Model}

We also analyze factors affecting farmers' participation decision and level of participation in small ruminants' market. To analyze the problem we employed a double- hurdle regression model and twelve explanatory variables were hypothesized to influence the probability of participation and level of market participation. However, before running the final regression analysis, all explanatory variables need to be checked for the existence of multi-collinearity using Variance Inflating Factor (VIF) by a Statistical Package known as Stata 14. Consequently, it suggests that, there is no serious multi-collinearity problem in the model, since there is no strong association among the hypothesized explanatory variables by considering VIF values of less than 10 and this depicted multicollinearity was not a problem.

Then, test for constant variance errors (homoschedasticity) pointed out using hettest command, and result from the Breusch-Pagan/Cook-Weisberg test show that the regression of the residuals on the predicted value reveals insignificant and it mean that there is no hetroschedasticty trouble. Since, the regression merely requires that the residual (errors) be identically and independently distributed, this test attested to accept the hypothesis of constant variances.

Moreover, model specification test whether that arise of proper functional form and either there is omitted or irrelevant variables included was also checked using linktest and estat ovtest commands and the result illustrated that the model is correctly specified and/or it indicates that there is no model specification error.

Finally, the analysis was done on empirical test of the double hurdle versus the Tobit model. The decision criteria of log likelihood test were used to choose between the double- hurdle model and tobit model. Then, the test statistics by far exceeds the critical $\chi^{2}$ (12) value of 23.34 at $5 \%$ level of statistical significance in favor of the double-hurdle model. Therefore, the tests reject the use of the simultaneous decision, i.e. Tobit model. Likewise, Heckman two stage estimation model was also tested for its advantage of selectivity bias correction using the inverse Mill's ratio (0.590). This was insignificant and it suggested that there was no sample selection bias that would result if the level of participation had been estimated without taking into account the participation decision on small ruminants. Hence, no need to use the Heckman selection model. 
Six explanatory variables were found that significantly influenced small ruminants' market participation among other independent variables (Table 4).

Table 4. Determinants of market participation of small ruminants' farmers result from Double Hurdle model (first-hurdle)

\begin{tabular}{lll}
\hline Variables & Coefficient & Standard Error \\
\hline Region & & \\
2 & -.017 & .018 \\
3 & $-.058^{* * *}$ & .022 \\
4 & $-.087 * * *$ & .026 \\
5 & -.026 & .021 \\
Sex of household head & .008 & .018 \\
Age of household head & -.000 & .001 \\
Educational status & -.007 & .015 \\
Family size & -.001 & .003 \\
Land size & -.000 & .016 \\
Distance to market & $.007 * *$ & .003 \\
Market information access & $.026^{*}$ & .014 \\
Credit access use & $.063 * * *$ & .015 \\
Distance to Vet. Service & $.134 * * *$ & .002 \\
Extension contact & $.002 * * *$ & .000 \\
Other animal sale(TLU) & .000 & .007 \\
Constant & $.104 * *$ & .046 \\
\hline
\end{tabular}

$* * *, * *$, and $*$ indicate statistical significance at $1 \%, 5 \%$, and $10 \%$, respectively.

Source: Authors collection

Five explanatory variables were also found that significantly influenced level of small ruminants market participation among other independent variables (Table 5).

Table 5. Determinants of quantity of small ruminants supplied (Result from Double Hurdle model) (second-hurdle)

\begin{tabular}{lll}
\hline Variables & Coefficient & Standard Error \\
\hline Region & & \\
2 & .145 & .137 \\
3 & $.517^{* * *}$ & .170 \\
4 & -.272 & .170 \\
5 & $.317^{* *}$ & .155 \\
Sex of household head & .023 & .133 \\
Age of household head & .007 & .005 \\
Educational status & .054 & .113 \\
Family size & $-.041^{*}$ & .023 \\
Land size & -.192 & .125 \\
Distance from market & $-.041^{* *}$ & .020 \\
Market information access & -.135 & .104 \\
Credit access use & $.220^{*}$ & .116 \\
Distance from Vet. Service & $.432^{* * *}$ & .028 \\
Extension contact & .007 & .004 \\
Sheep/goat salughtered(TLU) & .307 & .591 \\
Constant & $-1.114^{* * *}$ & .365 \\
Insigma & & \\
_const & $-2.033^{* * *}$ & .032 \\
Sigma & .1313 & .004 \\
\hline
\end{tabular}

$* * *, * *$, and $*$ indicate statistical significance at $1 \%, 5 \%$, and $10 \%$, respectively.

Source: Authors collection 
Region: Region significantly and negatively influenced small ruminants' participation to market at $1 \%$ level of significance. The negative sign shows being the Amhara region producers of small ruminants significantly decrease small ruminants participation to market by $5.8 \%$ and $8.6 \%$ as compared to that of small ruminants producers participating to the market in SNNP and Somalia region respectively, keeping other variables constant. This may indicate that, small ruminants' producers in Amhara region might consider shoat as their asset and/ or associated with lack of market access and price decrease for their product as compared to SNNP and Somalia region.

On the Contrary, the result of the region regression model comparing Amhara region level of small ruminants market participation decision indicated that, significantly and positively influences small ruminants level of market participation producers at SNNP and Tigray region at 1\% and 5\% levels of significant holding all other explanatory variables constant, respectively. The positive sign reveals Amhara region small ruminants producer have high level to market participation in contrast to SNNP and Tigray small ruminants producers by $51.7 \%$ and $31.7 \%$ respectively. The reason behind might be in the Amhara region producers be better endowed with resources like sheep and goat than SNNP and Tigray region small ruminants producers and this may be because, there is large number occurrence of small ruminants in the region.

Access to credit service: The model result show that use of credit service significantly and positively influences market participation and level of small ruminants market participation at $10 \%$ and $1 \%$ respectively. As compared to non-users of credit, credit user household's market participation and level of participation increases by $22.04 \%$ and $6.26 \%$ respectively, holding all other explanatory variables constant. Use of credit service is important instrument to increase the market participation and level of small ruminants market participation. Households who used credit service purchase the necessary input at required time which increases the market participation. From this result it can be stated that those farmers who have access to formal credit are more likely to participate in small ruminants market than those who have no access to formal credit. So, strengthening and expansion of credit institution in the rural area is of paramount importance to address credit needs of farming community. Fikru, Efa \& Hailu. (2017) also showed the significance relationship between credit access and market participation decision but negatively.

Distance to the market: As expected, distance to market center has negatively and positively associated with farmer's participation to the market and to the level of small ruminants market respectively at a significant level of $5 \%$ holding all other explanatory variables constant. The model result indicate that as the distance from market center increases by one $\mathrm{km}$, the probability of participation in market decrease by $4.2 \%$ and the level of participation increase by $3.7 \%$. The implication is that the longer the distance between farmers' residence and the market center, the lower will be the probability of participating to the market and the higher to be involved in the level of small ruminants market (i.e, producers are unwilling not to return with the animals). This finding is in line with other studies. Study by Bayissa (2014) also shows in the study distance to the market has a negative and significance relation with improved teff technologies adoption and intensity of use.

Distance to veterinary services: This variable influences both market participation and level of participation positively and significantly at $1 \%$ significance level by holding all the independent variables constant. The result shows that as the distance from their residence to the veterinary service increases by a kilometer, the market participation and the level of small ruminants market participation increases by $43.21 \%$ and $13.43 \%$, respectively. This may be due to the fact that the further the veterinary service areas, the higher would be the producers interest to participate and level of participation in a market because of the fact that producers are unwilling to incur additional cost to get facilities.

Extension contact in number of days with a year: Number of days extension contact affects the market participation and the level of market participation of small ruminants as expected positively at a significant level of $10 \%$ and $1 \%$ respectively holding all other explanatory variables constant. The result confirms as extension contact increases by a day, the probability of participation and the level of participation in small ruminants' market increase by $0.67 \%$ and $0.24 \%$ respectively. Households who have extension contact at required time has more favor to participate in the market. Ali (2017) also shows the positive and significance relationship between extension contact and market participation decision.

Access to market information: Access to market information significantly and positively influences intensity of small ruminant's participation to the market at $10 \%$ significance level. Marginal effect confirms that as compared to households who have no access to market information, households who have access to market information increases small ruminants market participation decision by $2.6 \%$, all other factors held constant. Market information is vital instrument during marketing because it informs the farmers about marketing conditions. 
Farmers who have price information prior to marketing tend to sell more of their produce than those without. The finding is consistent with the results of Nugusa (2018) who found the existence of positive relationship between the market information and maize market participation decision.

Family size: Family size was found to influence the small ruminants market participation negatively at $10 \%$ significance level as expected. This can be because of the fact that if the family number increases the small ruminants market participation is decreasing by holding all other factors constant. Because of this reason, some more addition of a labor force will decrease small ruminants' market participation by $4.1 \%$ and the negative effect of the variable shows that as the number of household members increased some more part of small ruminants produce is allocated for household consumption. The study of Ali (2018), Ayantu (2018) and Nugasa (2018) agrees with 'this result.

\section{Summary and Recommendations}

\subsection{Summary}

This study was aimed at analyzing factors affecting market participation and level of participation of small ruminant's producers in Ethiopia. The study employed cross-sectional data collected from a total of 1120 small ruminant producers.

Double hurdle was used to identify factors influencing small ruminants' market participation decision and level of participation of the sample households. The result indicated that small ruminants' market participation decision was significantly affected by region, distance to market, credit use, distance to veterinary service, frequency of extension contact and market information. Region, distance to the market and family size affected small ruminants' market participation significantly and negatively. On the other hand, region, credit access, distance to veterinary service, and frequency of extension contact affected market participation significantly and positively.

Level of small ruminants supplied to market was significantly and positively affected by region, distance to market areas, access to credit, access to veterinary service, frequency of extension contact, and access to market information. It was also affected negatively and significantly by region.

\subsection{Recommendations}

Based on the finding of this study, the following recommendations are relevant to improve and develop sustainable small ruminant's value chain that are adaptable locally and expected to increases competitiveness.

Distance to veterinary service and frequency of extension contact significantly and positively affected both market participation and level of shoat market participation. The study suggested need to strengthening the existing improved health services will enhance sheep and goat production. Government should also pay attention on small ruminants producers among the market actors via efficient extension service, and extension workers and other related services.

Distance from the market affected significantly and negatively the small ruminants market participation. Therefore, developing market infrastructure such as building market places and improving road to reduce trekking time, transportation costs and other marketing costs can improve access to small ruminants' market. Distance from the market also affect positively and significantly small ruminants supply to the market; this may also indicate the need to facilitate a long term relationship with different actors in order to get reasonable price for the producers.

Family size significantly and negatively affected small ruminants' market participation. Therefore, health extension workers and other stakeholders need to give attention to strengthening and control policies on improving rural family planning to enhance farmers' livelihood and market participation.

Credit access and access to market information also affect positively and significantly the level of small ruminants market participation. Thus, concerned bodies need to give attention to benefit farmers through providing credit for enhancing small ruminant farmers to supply quality product. So, this encourages producers to search the way to get additional income from the market supply. Farmers who got additional income can purchase the necessary inputs at required time and could increase their productivity which increases the market supply. Thus, micro finance institutions have to cooperate farmers to increase the income of farmers. Similarly, obtaining perfect information and access to market information will raise the bargaining powers of producers. Therefore, woreda agriculture offices and marketing departments should facilitate farmers to get a weekly price on small ruminants market.

Since there are occurrence of large number of small ruminants in the country, region also significantly affected 
market participation and Level of small ruminants marketed in the nation. This ensure even if there is differentiation on resource endowment among the regions, equal participation and benefit for small ruminants value chain effort should be made to encourage regions small ruminates producers. Therefore, government or any other bodies who are concerned on small ruminants product should help producers on Improving the accessibility of market places and Strong linkages between producers and buyers are crucial.

\section{Acknowledgements}

The authors would like to thank International Center for Agricultural Research in the Dry Areas (ICARDA) and Ministry of Education for financial support for this research.

\section{References}

Ali, T. (2017). Value Chain Analysis of Milk: The Case of DessieZuria District, South Wollo Zone, Northern Ethiopia. Master's thesis, University of Jimma, Jimma, Ethiopia. p. 136.

Ayantu, L. (2018). Value Chain Analysis of Sheep in Tiyo District of Arsi Zone, Oromia National Regional State. Master's thesis, University of Haramaya, Haramaya, Ethiopia. p. 94.

Bayissa, G. (2014). A Double-Hurdle Approach to Modeling of Improved Tef Technologies Adoption and Intensity Use in Case of Diga District of East Wollega Zone. Global Journal of Environmental Research, $8(3), 41-49$.

Chiemela P., Seung-Hwan, L., Egbu, C., Prabuddha M., \& Jun, H. L. (2018). Review on challenges, opportunities and genetic improvement of sheep and goat productivity in Ethiopia. Journal of Animal Breeding and Genomics, 2, 1-8. https://doi.org/10.12972/jabng.20180015

Cragg, J. (1971). Some statistical models for limited dependent variables with application to the demand for durable goods. Econometrica, 39(5), 829-844. https://doi.org/10.2307/1909582

CSA (Central Statistical Agency) Agricultural Sample Survey. (2017). Volume II. Report on livestock and livestock characteristics (private peasant holdings). CSA, Addis Ababa, Ethiopia.

Daniel, D., Solomon, G., \& Getachew, L. (2013). Analysis of goat value chains in Tanqua Abergelle district, Tigray, Ethiopia. Addis Ababa: ICARDA. p. 45.

Dessalegn, L. (2018). Goat Production and Marketing System in Ethiopia. European Journal of Applied Sciences $10(2), 48-54$.

Duguma, G., Kifle, D., Temesegen, J., Ayinalem, H., Duncan, J., \& Getachew L. (2013). Analysis of sheep value chains in Horro district, Oromia region, Ethiopia. Addis Ababa: ICARDA.44p.

Esther, L., \& Gaudiose, M. (2016). Market participation by smallholder rice farmers in Tanzania: a double hurdle analysis. Studies in Agricultural Economics 118(2016), 112-115. https://doi.org/10.7896/j.1528

Eyob, E., \& Zewudu, A. (2016). Review on live animal and meat export marketing system in Ethiopia: challenges and opportunities. Journal of Scientific and Innovative Research, 5(2), 59-64.

Fikru, T., Efa, G., \& Hailu, M. (2017). Analysis of Sesame Marketing Chain in Case of Gimbi Districts. Ethiopian Journal of Education and Practice, 8(10).

Greene, W. (2000). Econometric Analysis. Englewood Cliffs, NJ: Prentice Hall.

Hosri, C., Tabet, E., \& Nehme, M. (2016). Goat and sheep products value chain analysis in Lebanon. In: M. Napoléon, H. BenSalem, J. P. Boutonnet, cos A. López-Fran \& D. Gabiña (Eds.), The value chains of Mediterranean sheep and goat products (pp. 61-66). Organization of the industry, marketing strategies, feeding and production systems. Zaragoza: CIHEAM.

Matawork, M. (2016). Review on Small Ruminant Production, Marketing and Constraints in Ethiopia. Advances in Life Science and Technology, 48.

McDowell, A. (2003). From the Help Desk: Hurdle Models. Stata Journal, 3(2), 178-84. https://doi.org/10.1177/1536867X0300300207

Mohammed, A. (2019). Production of hide and skin in Ethiopia; Marketing Opportunities and Constraints. A review paper Cogent Food \& Agriculture, 5(1). https://doi.org/10.1080/23311932.2019.1565078

Mueller, B., Acero, F., \& Estruch, E. (2017). Creating Employment Potential in Small-Ruminant Value Chains in the Ethiopian Highlands. FAO Animal Production and Health Working Paper No. 16, Rome, FAO.

Namazzi, S., Ekere, W., Kyazze, F., \& Bareeba, F. (2015). Determinants of participation of smallholder farmers 
in marketing of grain amaranth in Kamuli District, Uganda. Journal of Agricultural Economics and Development, 4(5), 075-082.

Nugusa, A. (2018). Analysis of Maize Value Chain: The Case of Guduru Woreda, Horro Guduru Wollega Zone of Oromia Regional State, Ethiopia, MSc Thesis. Haramaya University, Ethiopia. p. 107.

Shewangzaw, A., Aschalew A., Addis, G., Malede, B., \& Assemu, T. (2018). Small Ruminant Fattening Practices in Amhara Region, Ethiopia. Agric \& Food Secur, 7, 64. https://doi.org/10.1186/s40066-018-0218-9

Woodridge, J. (2002). Econometric Analysis of Cross-section and Panel Data. MIT Press, USA.

Wooldridge., J. (2006). Introductory Econometrics: A Modern Approach. Mason, OH: Thomson South-Western. Third Edition.

\section{Copyrights}

Copyright for this article is retained by the author(s), with first publication rights granted to the journal.

This is an open-access article distributed under the terms and conditions of the Creative Commons Attribution license (http://creativecommons.org/licenses/by/3.0/). 